\title{
Limnologia by J G Tundisi and T Matsumura Tundisi
}

\author{
Bicudo, CEM.* \\ Seção de Ecologia, Instituto de Botânica, Divisão do Jardim Botânico de São Paulo \\ Av. Miguel Stefano, 3687, CP 400, CEP 04301-012, São Paulo, SP, Brazil \\ *e-mail: cbicudo@terra.com.br
}

It would be difficult to start this review without congratulating the Tundisi husband and wife team, José Galizia and Takako, for the text Limnologia they have just published. This is an unquestionably complete, upto-date and extremely information-dense compendium. The work is made up of twenty chapters, ranging from the definition of Limnology up to a concise and absolutely real view of the future of basic research in the area and the application of such science in the present world. Each chapter deals with its subject in a linear, very didactic and information-rich way, showing the authors' profound knowledge and their eternal resolve, with veritable conviction, to convey the information in an unrestricted way. As well as focussing on the history of Limnology, the first ten chapters focus on water as a substrate, the origin of lakes and aquatic biota and their interaction with environmental factors. The following five chapters deal with the functioning mechanisms of the main aquatic systems of the globe, their dynamics, variability and characterisation. The next two chapters offer a combined view of limnological studies in South and Central America, in the African continent and in the temperate regions of the world. Of the last three chapters, two treat the impacts that human activities provoke in water resources and the consequent need for recuperating these environments; and the third deals with the various approaches, study methods, and the present and future of Limnology in the world. Admirably, the authors have been attentive to introducing into the text information which originates from studies carried out in the Tropics and mainly, from Brazil. Numerous works by Brazilian authors have been included in the text, an aspect that makes the Tundisis' book unique. But, Limnologia is not a compendium of theories that are extremely useful only to professionals and postgraduate students in Limnology. It also brings precious information to those who use knowledge in an applied way, such as water resource technicians and managers. So neither will Limnologia be restricted to the geographical limits of Brazil. It is certain that it will be adopted as a text or reference work in other universities and institutions of scientific research in all countries where Portuguese or Spanish is the native tongue. The Tundisis were very fortunate in choosing Oficina de Textos to bring this book into being. Oficina's professional service has shown itself to be supreme. And I cannot close this review without congratulating, once again, the Tundisis for yet another endeavour, for they have exceeded the best of expectations. Congratulations also, then, to our Brazil, for having these two scientists in its scientific community, and for now being able to count on Limnologia in its specialized literary collection.

\section{Reference}

TUNDISI, JG. and MATSUMURA-TUNDISI, T. 2008. Limnologia. Oficina de Textos. 632 p. 